\title{
ANALISIS PENGARUH GAYA KEPEMIMPINAN DAN ETOS KERJA TERHADAP KINERJA KARYAWAN MELALUI MOTIVASI SEBAGAI VARIABEL INTERVENING
}

\author{
L. Lamere ${ }^{1}$, C. Kirana ${ }^{2}$, H. Welsa ${ }^{3}$ \\ 1,2,3 Jurusan Manajemen, Universitas Sarjanawiyata Tamansiswa, Yogyakarta \\ e-mail: luckyvanlam23@gmail.com, chandrakna@gamil.com, h.welsaust@yahoo.com
}

\begin{abstract}
Abstrak
Penelitian bertujuan untuk mengetahui analisi pengaruh Gaya Kepemimpinan dan Etos Kerja terhadap Kinerja Pegawai Badan Perencanaan Pembangunan Daerah Kabupaten Kepulauan Tanimbar dengan Motivasi sebagai Variabel Intervening. Objek dalam penelitian ini adalah seluruh pegawai tetap BAPPEDA Kabupaten Kepulauan Tanimbar sebanyak 50 orang. Metode pengumpulan data dalam penelitian ini dilakukan dengan cara kuesioner (angket), analisis data dalam penelitian ini adalah Partial Least Square (PLS) dengan menggunakan sofware SmartPLS 3.2.8. Adapun hasil dari penelitian ini yaitu. Gaya Kepemimpinan tidak berpengaruh signifikan terhadap kinerja namun berpengaruh signifikan terhadap motivasi. Etos Kerja memiliki pengaruh secara signifikan terhadap kinerja, namun tidak berpengaruh secara signifikan terhadap motivasi. Motivasi tidak berpengaruh signifikan terhadap kinerja, Gaya Kepemimpinan tidak berpengaruh signifikan terhadap kinerja melalui motivasi dan Etos Kerja tidak berpengaruh signifikan terhadap kinerja melalui motivasi.
\end{abstract}

Kata Kunci: Gaya Kepemimpinan, Etos Kerja, Kinerja Pegawai, Motivasi.

\section{Abstract}

This study aims to determine the effect of Leadership Style and Work Ethic on Employee Performance of the Tanimbar Islands District Regional Development Planning Agency with motivation as an intervening variable. The object of this research is all permanent employees of BAPPEDA Tanimbar Islands Regency as many as 50 people. The data collection method in this study was carried out by means of a questionnaire (questionnaire), data analysis method in this study is Partial Least Square (PLS) using the SmartPLS 3.2.8 software. The results of this study are. Leadership style has no significant effect on performance but has a significant effect on motivation. Work ethic has a significant effect on performance, but does not significantly influence motivation. Motivation has no significant effect on performance, Leadership Style does not have a significant effect on performance through motivation and Work Ethic does not have a significant effect on performance through motivation.

Keywords: Leadership Style, Work Ethic, Employee Performance, Motivation.

\section{Pendahuluan}

Terlihat dari pentingnya sumber daya manusia sehigga, perusahaan harus memperhatikan tingkat kemampuan kepemimpinan yang baik dan benar kepada seluruh pegawainya agar dapat terciptanya iklim kekeluargaan yang baik dan pada akhirnya dapat meningkatkan kinerja pegawai. Kepemimpinan yang baik dapat mendorong setiap karyawan dan organisasi untuk dapat mencapai tujuan dan target yang di tetapkan (Hendriyaldi, (2019). Selain itu menurut Arsad, (2017). Etos kerja yang ada pada diri setiap orang mempunyai dorongan tersendiri agar mereka bergairah untuk bekerja. Selain itu suasana lingkungan kerja yang aman juga akan meningkatkan kinerja pegawai untuk dapat melaksanakan dan menyelesaikan setiap pekerjaan yang ditugaskan dengan baik. Lingkungan kerja yang baik dapat mempengaruhi hubungan kerja yang dapat mengikat setiap pegawai yang ada di dalam lingkungannya.

Wowor et al., (2019). Dalam melakukan suatu pekerjaansetiap karyawan membutuhkan motivasi yang ada pada dirinya agar timbul suatu semangat atau kegairahan dalam bekerja. Motivasi berasal dari kata latin, yakni movere, yang berarti dorongan atau menggerakkan. Berdasarkan fenomena-fenomena yang terjadi antara lain pegawai PNS yang tidak 
memegang teguh amanah dalam melaksanakan tugas pokok dan kewajibannya, pegawai yang tidak hadir tanpa keterangan akan mengalami kerugian akibat terhambatnya penyelesaian pekerjaan, penurunan efisiensi. Giantari \& Riana, (2017). Upaya perusahaan untuk meningkatkan kinerja karyawan yaitu melalui motivasi kerja yang diberikan, karena pada dasarnya motivasi kerja dapat menjadi hal-hal yang mengakibatkan, menyalurkan, mendukung perilaku karyawan agar mau bekerja lebih giat dan antusias sehingga akan mencapai kinerja yang optimal.

Pimpinan harus berusaha menciptakan kondisi etos kerja secara kondusif sehingga terciptanya kinerja yang baik. Kemampuan BAPEDA masih terbatas, sikap dan perilaku masih perlu di tingkatkan disamping itu perlu ada motivasi dari pimpinan. Organisasi memiliki tanggung jawab memberikan dorongan terhadap pegawai, sehingga dapat bekerja dengan secara tekun sehingga mencapai target agar mendapatkan kinerja pegawai sesuai yang diharapkan. Fatchurozi et al., (2018). Kepemimpinan adalah seorang yang memiliki pemikiran dan yang berperilaku secara berkelompok dengan anggotanya dan memakai cara ataupun gaya yang bermacam- macam, sehingga kepemimpinan dapat mendorong kekuatan dalam setiap individu, memberikan motivasi dan mengkoordinasikan perusahaan untuk tercapinya tujuan perusahaan. Ketercapaian dan keberhasilan suatu lembaga atau organisasi ditentukan oleh kemampuan kepemimpinan. Melalui kemampuan, inovatif, gagasan dan perilaku kepemimpinan seseorang mampu menghantarkan organisasi mencapai tujuan.

Veliu et al., (2017). Gaya kepemimpinan pada suatu organisasi merupakan salah satu faktor yang berperan penting dalam meningkatkan atau memperlambat minat dan komitmen individu dalam organisasi. Pemimpin yang paling sukses memiliki integritas, mereka menginspirasi orang dengan visi bersama tentang masa depan, mereka menetapkan tujuan yang jelas dan memotivasi orang ke arahnya, mereka mengelola pengiriman, dan mereka berkomunikasi dengan baik dengan tim.

Salahudin et al., (2016) Etika adalah salah satu masalah paling kritis dalam bisnis dan khususnya dalam manajemen sumber daya manusia. Budaya etika yang baik dalam suatu organisasi akan memberikan arahan dan bimbingan dalam berbagai bidang guna membangun karyawan yang bersatu, harmonis dan beretika. Akan tetapi, tidak ada pedoman atau standar etika yang mutlak, sesuai, dan dapat diterapkan di setiap perusahaan.

Ekhsan, (2019). Motivasi merupakan sutu proses untuk menunjukan kemampuan individu, ketekunan dari upaya menuju pencapaian tujuan. Tanpa motivasi, seorang pegawai tidak dapat mencapai standar atau dapat melampaui standar karena apa yang menjadi motif dan motivasinya tidak terpenuhi. Menurut Rukmana, (2020). Motivasi juga menjadi faktor penting yang harus dimiliki oleh setiap karyawan. Setiap karyawan memiliki berbagai jenis minat dalam bekerja, inovasi dapat menjadi pendorong bagi seseorang untuk menyelesaikan tugas dan tanggung jawabnya di tempat kerja dan seseorang dapat dengan senang hati melakukan pekerjaannya dengan baik. Selain itu faktor internal merupakan faktor yang berasal dari dalam diri karyawan, yang meliputi kepuasan kerja, motivasi dan komitmen organisasional, maka ini dinilai menjadi sangat penting sekali untuk menaikan kinerja karyawan. Sedangkan faktor eksternal merupakan faktor yang berasal dari luar diri karyawan, meliputi kepemimpinan, budaya organisasi, keamanan dan keselamatan (Febrianti \& Triono, 2020). Kinerja mengacu pada kadar pencapaian tugas-tugas yang membentuk pekerjaan seluruh karyawan. Kinerja juga merefleksikan seberapa baik para karyawan memenuhi persyaratan sebuah pekerjaan yang sudah ditentukan oleh perusahaan sesuai dengan bidang kerjanya masing- masing (Batubara, 2020).

Berdasarkan fenomena-fenomena yang terjadi antara lain pegawai PNS yang tidak memegang teguh amanah dalam melaksanakan tugas pokok dan kewajibannya, pegawai yang tidak hadir tanpa keterangan akan mengalami kerugian akibat terhambatnya penyelesaian pekerjaan, penurunan efisiensi, tidak adanya inisiatif untuk melaksanakan tugasnya secara langsung cenderung harus berdasarkan perintah atasan baru mau melaksanakannya, masih adanya pegawai yang menunda-nunda pekerjaan sehingga membuat pekerjaan menumpuk, kurangnya keahlihan dalam memahami dan melaksanakan tugas dan kewajibannya serta pengalaman kerja yang kurang memberikan kontribusi pada bidang tugas. 
Berdasarkan uraian latar belakang permasalahan di atas maka rumusan masalah dalam penelitian ini adalah sebagai berikut : (1) Apakah gaya kepemimpinan berpengaruh terhadap kinerja pegawai. (2) Apakah etos kerja berpengaruh terhadap kinerja pegawai. (3) Apakah motivasi berpengaruh terhadap kinerja pegawai (4). Apakah gaya kepemimpinan, berpengaruh terhadap motivasi. (5) Apakah etos kerja berpengaruh terhadap motivasi. (6) Apakah gaya kepemimpinan berpengaruh terhadap kinejra pegawai dengan motivasi sebagai variabel intervening. (7) Apakah etos kerja berpengaruh terhadap kinerja pegawai dengan motivasi sebagai variabel intervening.

Tujuan khusu yang ingin dicapai dalam penelitian pada Pegawai Badan Perencanaan Pembangunan Daerah Kepulauan Tanimbar : (1) Mengetahui pengaruh gaya kepemimpinan terhadap kinerja pegawai. (2) Mengatahui pengaruh etos kerja terhadap kinerja pegawai. (3) Mngetahui pengaruh motivas terhada kinerja pegawai. (4) Mengetahui pengaruh gaya kepemimpinan terhadap motivasi. (5) Mengetahui pengaruh etos kerja terhadap motivasi (6) Mengetahui pengaruh gaya kepemimpinan terhadap kinerja karyawan dengan motivasi sebagai variabel intervening. (7) Mengetahui pengaruh etos kerja terhadap kinerja karyawan dengan motivasi sebagai variabel intervening.

Adanya penelitian ini diharapkan dapat memberikan manfaat sebagai berikut : (1) Secara Teoritis. Bagi penulis. Hasil penelitian ini diharapkan dapat berguna dalam menambah atau memperbanyak wawasan pengetahuan baik teori maupun praktek, belajar menganalisi dan melatih daya fikir dalam mengambil kesimpulan atas permasalahan yang ada di dalam Bada Perencanaan Pembangunan Derah Kepulauan Tanimbar. (2) Secara Praktis. (a) Bagi BAPPEDA .Penelitian ini diharapkan dapat memberikan informasi dan masukan yang positif mengenai pengaruh Gaya kepemimpinana dan etos kerja terhadap kinerja pegawai melalui motivasi di tempat penelitian yang dilakukan. (b) Bagi peneliti lain. Memberikan referensi yang ingin meneliti tentang kemungkinan faktor-faktor lain yang berpengaruh terhadap kinerja pegawai melalui motivasi

\section{Metode}

Subjek dalam penelitian ini adalah Badan Perencanaan Pembangunan Daerah Kepulauan Tanimbar di JI. Ir. Soekarno, Kecamatan Tanimbar Selatan. Populasi dari penelitian ini adalah seluruh pegawai tetap kantor Badan Perencanaan Pembangunan Daerah Kepulauan Tanimbar yang meliputi Bidang Informasi Kepegawaian yaitu sebanyak 50 orang. Sampel dalam penelitian yaitu. Sampel menurut Wiyono, (2020), merupakan bagian populasi yang terwakili dan akan diteliti atau sebagian jumlah dari karakteristik yang dimiliki oleh populasi yang terwakili dan akan diteliti atau sebagian jumlah dari karakteristik yang dimiliki oleh populasi yang terwakili. Karena populasi berjumlah berjumlah 50 responden, metode penarikan sampel dalam penelitian adalah metode sensus yang digunakan untuk menjaring seluruh populasi sebagai responden, dimana seluruh pegawai BAPPEDA Kepulauan Tanimbar yang berjumlah 50 orang ditetapkan sebagai responden.

Penelitian yang dilakukan menggunakan data primer yang berasal dari objek penlitian yaitu pegawai Kantor Badan Perencanaan Pembangunan Daerah Kepulauan Tanimbar. Data primer diperoleh dari sumber data yang memberikan data secara langsung (responden) kepada peneliti melalui penyebaran daftar pertanyaan (kuesioner) berdasarkan variabel yang diteliti. Alat analisis ini digunakan adalah Partial Least Square (PLS), yaitu SEM yang berbasis variance, dengan software SmartPLS 3.2.8.

\section{Hasil dan Pembahasan}

Uji Indikator (Mesurement Model/ Outer Model)

Uji indikator atau disebut Outer Model atau measurement model. Uji indikator dalam model ini menspesifikasi hubungan antar variabel laten dengan indikator - indikatornya atau dapat dikatan bahwa outer model mendefinisikan bagaimana setiap indikator berhubungan dengan variabel latennya. Dari uji indikator ini diperoleh output validitas dan reliabilitas model yang diukur dengan kriteria: Convergent Validity, Discriminant Validity dan Composite Reliability. Model pengujian Measurement Model/Outer Model (Model Sebelum Uji Indikator) pada gambar 4.1 


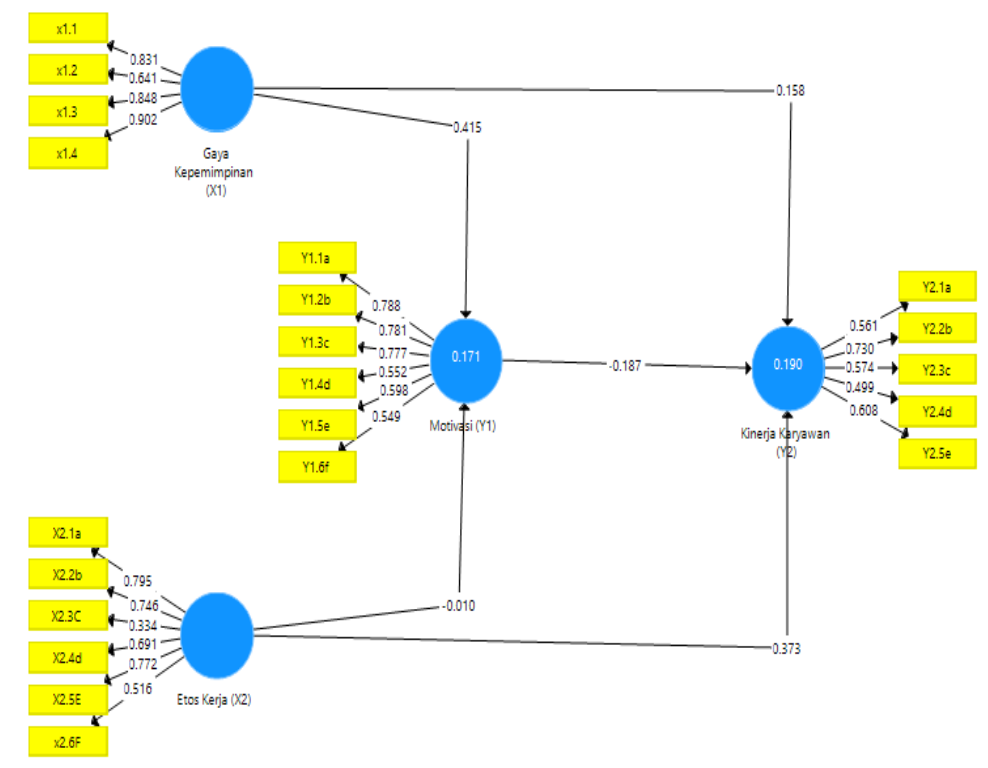

Gambar 1 Model Awal Algoritma Sumber: Data SPLS 3.2.8

Gambar 4.1 merupakan hasil kalkulasi algoritma telah menunjukan hasil perhitungan dari setiap indikator pada setiap variabel ke variabel yang lain. Namun dapat diketahui bahwa terdapat indikator yang tidak memenuhi syarat nilai loading dengan kriteria; nilai loading > 0,70 . Maka indikator yang memenuhi kriteria harus dihilangkan. Berikut hasil dari penghapusan indikator yang tidak memenuhi kriteria.

\section{Convergent Validity}

Convergent Validity diukur dari korelasi antara skor indikator dengan konstruknya. Indikator dianggap valid jika memiliki nilai korelasi diatas 0,70 , apabila indikator tidak memenuhi syarat maka harus dibuang atau dihilangkan.

Tabel 1 Outer Loading (Convergent Validity)

\begin{tabular}{|c|c|c|c|c|c|c|}
\hline \multirow{3}{*}{$\begin{array}{c}\text { Outer Loading } \\
\text { (Convergent } \\
\text { Validity) }\end{array}$} & \multirow[t]{4}{*}{ Indikator } & \multicolumn{5}{|c|}{ Hasil } \\
\hline & & \multicolumn{2}{|c|}{ Variabel Laten } & & & Keterangan \\
\hline & & X1 & X2 & Y1 & \multirow[t]{2}{*}{ Y2 } & \\
\hline Gaya & & & & & & \\
\hline \multirow[t]{4}{*}{ Kepemimpinan } & X1.1a & 0,831 & & & & Vlid \\
\hline & $X 1.2 b$ & 0,641 & & & & Tidak Valid \\
\hline & $X 1.3 c$ & 0,848 & & & & Valid \\
\hline & $\times 1.4 d$ & 0,902 & & & & Valid \\
\hline \multirow[t]{6}{*}{ Etos Kerja } & X2.1a & & 0,795 & & & Valid \\
\hline & $X 2.2 b$ & & 0,746 & & & Valid \\
\hline & $\times 2.3 c$ & & 0,334 & & & Tidak Valid \\
\hline & $X 2.4 d$ & & 0,691 & & & Tidak Valid \\
\hline & $\mathrm{X} 2.5 \mathrm{e}$ & & 0,772 & & & Valid \\
\hline & $X 2.6 f$ & & 0,516 & & & Tidak Valid \\
\hline \multirow[t]{6}{*}{ Motivasi } & Y1.1a & & & 0,788 & & Valid \\
\hline & Y1.2b & & & 0,781 & & Valid \\
\hline & Y1.3c & & & 0,777 & & Valid \\
\hline & Y1.4d & & & 0,552 & & Tidak Valid \\
\hline & Y1.5e & & & 0,598 & & Tidak Valid \\
\hline & Y1.6f & & & 0,549 & & Tidak Valid \\
\hline
\end{tabular}




\begin{tabular}{|c|c|c|c|c|c|}
\hline \multirow{3}{*}{$\begin{array}{c}\text { Outer Loading } \\
\text { (Convergent } \\
\text { Validity) }\end{array}$} & \multirow[t]{3}{*}{ Indikator } & \multicolumn{4}{|c|}{ Hasil } \\
\hline & & Variabel Laten & \multirow[b]{2}{*}{ Y1 } & \multirow[b]{2}{*}{ Y2 } & \multirow[t]{2}{*}{ Keterangan } \\
\hline & & $X 1 \quad X 2$ & & & \\
\hline Kinerja & Y2.1a & & & 0,561 & Tidak Valid \\
\hline Karyawan & Y2.2b & & & 0,730 & Valid \\
\hline & Y2.3c & & & 0,574 & Tidak Valid \\
\hline & Y2.4d & & & 0,449 & Tidak Valid \\
\hline & Y2.5e & & & 0,608 & Tidak Valid \\
\hline
\end{tabular}

Berdasarkan tabel diatas, beberapa indikator setelah melalu uji convergent validiti dinyatakan valid karena nilai loadingnya $>0,70$. Sedangkan beberapa indikator dinyatakan tidak valid karena nilai loadingnya $<0,70$. Sehingga indikator yang tidak valid harus dikeluarkan atau dibuang.

\section{Discriminat Validity}

Discriminat Validity yang di ukur dari cross loading antara indikator dengan konstruknya. Indikator dinyatakan valid jika hubungan indikator dengan konstruknya lebih tinggi dibandingkan dengan hubungannya dengan konstruk yang lain. Discriminant validity dilakukan untuk memastikan bahwa setiap konsep dari masing-masing variabel laten berbeda dengan variabel lainnya. Model dikatakan mempunyai discriminant validity yang baik jika setiap nilai cross loading indikator dari sebuah variabel laten memiliki nilai loading yang lebih besar dibanding nilai loading jika dikorelasikan dengan variabel laten lainnya (Wiyono, 2020). Hasil pengujian discriminant validity sebagai berikut :

Tabel 2 Cross Loading (Discriminat Validity)

\begin{tabular}{|c|c|c|c|c|c|c|}
\hline \multirow{3}{*}{$\begin{array}{c}\text { Outer Loading } \\
\text { (Convergent } \\
\text { Validity) }\end{array}$} & Indikator & \multicolumn{5}{|c|}{ Hasil } \\
\hline & & \multicolumn{2}{|c|}{ Variabel Laten } & & & \multirow[t]{2}{*}{ Keterangan } \\
\hline & & $\mathrm{X} 1$ & $\mathrm{X} 2$ & Y1 & Y2 & \\
\hline Gaya & & & & & & \\
\hline \multirow[t]{4}{*}{ Kepemimpinan } & $\mathrm{X} 1.1 \mathrm{a}$ & 0,831 & 0,246 & 0,287 & 0,108 & Valid \\
\hline & $X 1.2 b$ & 0,641 & 0,118 & 0,168 & 0,023 & Tidak Valid \\
\hline & $X 1.3 c$ & 0,848 & 0,129 & 0,371 & 0,235 & Valid \\
\hline & $X 1.4 d$ & 0,902 & 0,252 & 0,428 & 0,112 & Valid \\
\hline \multirow[t]{6}{*}{ Etos Kerja } & $\mathrm{X} 2.1 \mathrm{a}$ & 0,121 & 0,795 & 0,071 & 0,223 & Valid \\
\hline & $X 2.2 b$ & 0,100 & 0,746 & 0,057 & 0,312 & Valid \\
\hline & $X 2.3 c$ & 0,066 & 0,334 & $-0,152$ & 0,107 & Tidak Valid \\
\hline & $X 2.4 d$ & 0,016 & 0,691 & $-0,101$ & 0,205 & Tidak Valid \\
\hline & $\mathrm{X} 2.5 \mathrm{e}$ & 0,249 & 0,772 & 0,173 & 0,396 & Valid \\
\hline & $X 2.6 f$ & 0,249 & 0,516 & 0,035 & 0,115 & Tidak Valid \\
\hline \multirow[t]{6}{*}{ Motivasi } & Y1.1a & 0,322 & 0,100 & 0,788 & $-0,065$ & Valid \\
\hline & Y1.2b & 0,429 & 0,151 & 0,781 & 0,041 & Valid \\
\hline & Y1.3c & 0,245 & 0,005 & 0,777 & $-0,188$ & Valid \\
\hline & Y1.4d & 0,215 & 0,058 & 0,552 & $-0,038$ & Tidak Valid \\
\hline & Y1.5e & 0,069 & $-0,081$ & 0,598 & $-0,072$ & Tidak Valid \\
\hline & Y1.6f & 0,165 & $-0,045$ & 0,549 & $-0,129$ & Tidak Valid \\
\hline \multirow[t]{5}{*}{ Kinerja Karyawan } & Y2.1a & 0,197 & 0,192 & 0,248 & 0,561 & Tidak Valid \\
\hline & Y2.2b & 0,100 & 0,317 & $-0,187$ & 0,730 & Valid \\
\hline & Y2.3c & 0,233 & 0,218 & 0,103 & 0,574 & Tidak Valid \\
\hline & Y2.4d & $-0,147$ & 0,198 & $-0,128$ & 0,449 & Tidak Valid \\
\hline & Y2.5e & 0,115 & 0,215 & $-0,099$ & 0,608 & Tidak Valid \\
\hline
\end{tabular}




\section{Composite Reliability}

Konstruk dinyatakan reliabel apabila composite reliaility memiliki nilai $\geq 0,70$ (Wiyono, 2020). Semua variabel laten dinyatakan reliabel karena nilai dari composite reliability diatas $\geq$ 0,70 , dapat dilihat pada tabel berikut:

Tabel 3 Composite Reliability

\begin{tabular}{lcc}
\hline Variabel & Composite Reliability & Keterangan \\
\hline Gaya Kepemimpinan & 0,900 & Reliabel \\
Etos Kerja & 0,840 & Reliabel \\
Motivasi & 0,865 & Reliabel \\
Kinerja Karyawan & 1,000 & Reliabel \\
\hline
\end{tabular}

4. Uji hipotesisi

Innier Model merupakan pengujian terhadap model Structual yang dilakukan berdasarkan hasil uji model struktural (Innier Model) yang meliputi output $\mathrm{R}^{2}$, koefisien parameter dan t-satatistik sebagai berikut:

Tabel 4 Tabel Uji Hipotesis

\begin{tabular}{|c|c|c|c|c|}
\hline Hipotesis & Koefisien & T-statistik & $P$-value & Status \\
\hline $\begin{array}{l}\text { H1:Gaya Kepemimpinan } \\
\text { terhadap Kineria }\end{array}$ & 0,093 & 0,468 & 0,642 & $\begin{array}{l}\text { Tidak } \\
\text { Terbukti }\end{array}$ \\
\hline H2: Etos Kerja berpengaruh terhadap Kinerja & 0,419 & 2,932 & 0,005 & Terbukti \\
\hline H3: Motivasi berpengaruh terhadap Kinerja & $-0,171$ & 1,057 & 0,295 & $\begin{array}{l}\text { Tidak } \\
\text { Terbukti }\end{array}$ \\
\hline $\begin{array}{l}\text { H4:Gaya Kepemimpinan } \\
\text { terhadap Motivasi }\end{array}$ & 0,399 & 4,171 & 0,000 & Terbukti \\
\hline H5: Etos Kerja berpengaruh terhadap Motivasi & 0,080 & 0,625 & 0,535 & $\begin{array}{l}\text { Tidak } \\
\text { Terbukti }\end{array}$ \\
\hline $\begin{array}{l}\text { H6: Gaya Kepemimpinan berpengaru terhadap } \\
\text { kinerja melalui Motivasi sebagai Variabel } \\
\text { Intervening }\end{array}$ & $-0,068$ & 0,907 & 0,369 & $\begin{array}{l}\text { Tidak } \\
\text { Terbukti }\end{array}$ \\
\hline $\begin{array}{l}\text { H7: Etos Kerja berpengaruh terhdap Kinerja } \\
\text { melalui Motivasi sebagai Variabel Intervening }\end{array}$ & $-0,014$ & 0,417 & 0,678 & $\begin{array}{l}\text { Tidak } \\
\text { Terbukti }\end{array}$ \\
\hline
\end{tabular}

$\mathrm{H1}$ : Gaya kepemimpinan tidak berpengaruh secara signifikan terhadap kinerja, karena berdasarkan nilai T-statistik $>$ t-tabel yaitu. T-statistik memiliki nilai sebesar 0,464 sedangkan nilai dari t-tabel sebesar 0,093. Jika dilihat dari nilai $P$-value memiliki nilai sebesar $0,645>0,05$ dari hasil tersebut dapat disimpulakan bahwa hipotesis pertama tidak terbukti. H2: Etos kerja berpengaruh signifikan terhadap kinerja karyawan, hal ini dilihat berdasarkan dari nilai Tstatistik >t-tabel yaitu. T-statistik meiliki nilai sebesar 2,932 sedangkan t-tabel memiliki nilai 0,419 . Jika dilihat dari $P$-value memiliki nilai sebesar $0,005<0,05$ sehingga dapat disimpulkan bahwa hipotesis kedua terbukti. H3: Motivasi tidak berpengaruh terhadap kinerja, ini dilihat dari nilai T-statistik >t-tabel, dimana T-statistik memiliki nilai sebesar 1,057 sedangkan t-tabel memiliki nilai sebesar 1,71 jika dilihat dari nilai $P$-value memiliki nilai sebesar $0,295>0,05$ sehingga dapat disimpulkan bahwa hipotesis ketiga tidak terbukti. H4: Gaya kepemimpinan berpengaruh secara signifikan terhadap motivasi dilihat dari nilai T-statistik $>t$-tabel yaitu. Tstatistik memiliki nilai sebesar 4,171 sedangkan t-tabel memiliki nilai sebesar 0,399 jika dilihat dari nilai $P$-value memiliki nilai $0,000<0,05$ sehingga dapat disimpulkan bahwa hipotesisi keempat terbukti. 
H5: Etos kerja tidak berpengaruh signifikan terhadap motivasi dapat dilihat dari nilai T-statistik $>$ t-tabel yaitu. T-statistik memiliki nilai 0,625 sedangkan t-tabel meiliki nilai 0,080 jika dilihat dari nilai $P$-value memiliki nilai 0,535>0,05 sehingga dapat disimpulkan hiposesis kelima tidak terbukti.H6:Gaya kepemimpinan tidak berpengaruh signifikan terhadap kinerja melalui motivasi sebagai variabel intervening diketahui dari nilai T-statistik >t-tabel yaitu.T-statistik memiliki nilai sebesar 0,907 sedangkan t-tabel memiliki nilai sebesar 0.68 jika dilihat dari $P$ value memiliki nilai $0,369>0,05$ sehingga dapat ditariki kesimpulan bahwa hipotesis keenam tidak terbukti. H7: Etos kerja tidak berpengaruh signifikan terhadap kinerja melalui motivasi sebagai variabel intervening dilihat diketahui dari nilai T-statistik $>$ t-tabel yaitu. T-statistik memiliki nilai sebesai 0,417 sedangkan t-tabel sebesar 0,14 jika dilihat dari $P$-value memiliki nilai 0,678 $>0,05$ sehingga dapat disimpulkan bahwa hipotesis ketuju tidak terbukti.

\section{Simpulan dan saran}

Berdasarkan hasil penilitian dapat ditarik kesimpulan-kesimpulan yang berkaitan analisi motivasi dan kinerja pegawai BAPPEDA Kepulaun Tanimbar sebagai berikut: (1) Gaya kepemimpinan tidak berpengaruh signifikan terhadap kinerja, hal ini diketahui dari nilai-nilai $P$-value $<0,05$ yaitu $0,642>0,05$. Sehingga gaya kepemimpinan tidak berpengaruh positif dan signifikan terhadap kinerja. (2) Etos kerja berpengaruh positif dan signifikan terhadap kinerja, hal ini diketahui dari nilai $P$-value yaitu $0,005<0,05$. Sehingga dapat dapat ditarik kesimpulan bahwa etos kerja berpengaruh positif dan signifikan terhadap kinerja. (3) Motivasi tidak berpengaruh secari positif dan signifikan terhadap kinerja, hal ini dapat dilihat dari niali $P$-value yaitu 0,295 >0,05. Sehingga motivasi tidak berpengaruh signifikan terhadap kinerja. (4) Gaya kepemimpinan berpengaruh positif dan segnifikan terhadap motivasi karyawan hal ini dilihat dari nilai $P$-value yaitu $0,000<0,05$. Sehingga gaya kepemimpinan berpengaruh posfitif dan signifikan terhadap kinerja karyawan. (5) Etos kerja tidak berpengaruh positif dan signifikan terhadap motivasi karyawan hal ini dapa dilihat dari nilai $P$-value yaitu meliki nilai 0,535 $>0,05$. Sehingga etos kerja tidak berpengaruh positif dan segnifikan terhadap motivasi karyawan. (6) Gaya kepemimpinan tidaka berpengaruh positif dan signifikan terhadap kinerja pengawai hal ini dilihat dari nilai $P$-value yaitu $0,369>0,05$. Sehingga gaya kepemimpinan tidak berpengaruh positif dan segnifikan terhadap kinerja pegawai memalui motivasi sebgai varial intervening. (7) Etos kerja tidak berpengaruh positif dan signifikan terhadpa kinerja pengawai, hal ini dilihat dari nilai $P$-value yaitu $0,678>0,05$. Sehingga etos kerja tidak berpengaruh positif dan signifikan terhadap kinerja pegawai memalui motivasi sebagai variabel intervening.

Berdasarkan hasil penelitian yang telah dijelaskan, maka saran yang dapat diberikan sebagai berikut: (1) Bagi BAPPEDA Kepulauan Tanimbar sebaiknya memperhatikan beberap instrumen yang telah diteliti, diantaranya adalah: (a) Variabel etos kerja memiliki pengaruh positif dan signifikan terhadap kinerja karyawan hal tersebut dilihat dari nilai P-Value dimana nilai P-Value sebesar 0,005 $<0,05$ selain itu, berdasarkan hasil analisi desktiptif pada variabe etos kerja masih ditemukan jawaban tidak setuju, 59 kali . Hasil ini menunjukan bahwa terdapat 59 responden yang tidak memberikan penilaian setuju dan sangat tidak setuju pada variabel etos kerja. Maka dapat disarankan agar atasan BAPPEDA Kepulaun Tanimbar mampu meningkatkan dalam menggerakan dan mendorong pegawai untuk disiplin dan bertanggungjawab pada masing - masing bidang pekerjaannya, dalam hal ini lebih memperhatikan kedisiplinan terhadap waktu kerja sehingga BAPPEDA tidak mengalami kerugian dalam menjalankan tugas dan tangung jawab pegawai. Hal ini dilakukan agar semua pegawai BAPPEDA Kabupaten Kepulauan Tanimbar mampu bertanggungjawab pada setiap tugas yang diembankan kepadanya dibidangnya masing - masing dengan etos kerja yang telah diterapkan. (b) Berdasarkan hasil analisis deskriptif pada variabel gaya kepemimpinan masih ditemukan jawaban sangat tidak setuju 8 kali sebanyak $1 \%$, tidak setuju sebanyak 37 kali atau $7 \%$ dan neral 100 kali atau $18 \%$. Hasil ini menunjukan bahwa masih banyak responden yang memberikan penilain sangat setuju dan setuju pada variabel gaya kepemimpinan. Maka dapat disarankan agar atasan BAPPEDA Kepulauan mempunyai sifat konsisten dan komitmen yang tinggi dan menunjukan sifat peduli kepada orang lain sehingga, pegawai BAPPEDA merasa lebih diakui. Selain itu pemimpin juga mampu menciptakan peluang bagi orang lain untuk meningkatkan pengetahuan dan keterampilan, dengan 
melibatkan pegawai dalam pengambilan keputusan. (c) Berdasarkan hasil analisis deskriptif pada variabel motivasi masih ditemukan jawaban sangat tidak setuju sebanyak 18 kali atau $2 \%$ dan jawaban tidak setuju 48 kali atau $6 \%$ dan jawaban netral yang diberikan responden sebnyak 162 kali atau 20\%. Hasil ini menunjukan bahwa masi terdapat 20\% responden yang tidak memberikan jawaban sangat setuju dan setuju terhadap variabel motivasi. Maka dapat disarankan agar BAPPEDA Kepulaun Tanimbar lebih memperhatikan motivasi baik internal maupun eksternal yang diberikan pada pegawai. Pemberian insentif atau kompensasi bagi pegawai yang menunjukan kinerja yang positif dan giat dalam bekerja Hal ini dilakukan agar semua pegawai BAPPEDA Kepulauan Tanimbar dapat bekerja lebih maksimal karena merasa lebih termotivasi dan lebih diharagi. (d) Berdasarkan hasil analisi deskriptif pada variabel kinerja masih ditemukan jawaban netral pada responden sebesar 155 kali atau 26\%, tidak setuju 67 kali atau 11\% dan jawaban sangan tidak sejutu 26 kali atau 4\%. Maka dapat disarankan agar BAPPEDA Kepulauan Tanimbar dapat mingkatkan gaya kepemimpinan yang baik, seprti loyatitas terhadap pegawai. Etos kerja yang tinggi, seperti lebih memperhatikan kedisiplinan waktu kerja pada saat jam kerja dan motivasi seperi gaji pegawai, agar semua pegawai pada BAPPEDA Kepulaun Tanimbar dapat meningkatakan kualitas kerja dan dapat mencapai sasaran yang telah ditetapkan. (e) BAPPEDA dalam mengambil suatu kebijakan yang berkaitan dengan pegawai, hendaknya dapat melibatkan pegawai dan mengetahui kemauan dan keluhan pegawai sehingga dapat mendukung motivasi kerja dan etos kerja yang tinggi. Dengan motivasi dan etos kerja yang tinggi dapat mempengaruhi peningkatan kinerja pegawai. (f) Berdasarkan hasil penyebaran kuisioner diketahui bahwa tingkat pendidikan sebagai besar pegawai BAPPEDA Kepulauan Tanimbar untuk SMA sebanyak 8 (16\%) dan diploma 3 sebanyak 8 (16\%). Maka disarankan agar BAPPEDA Kepulauan Tanimbar lebih mendorong pegawainya untuk meningkatkan kinerja guna melanjutkan pendidikan yang lebih tinggi bagi pegawai yang berprestasi, sehinnga kualitas pegawai lebih baik dan kinerjanya akan meningkat. (2) Bagi peneliti selanjutnya, agar tidak melalukaukan penelitian mengenai analisis pengaruh gaya kepemimpinan terhadap kinerja melalui motivasi sebagai variabale intervening mengingat, berdasarkan nilai efek total variabel gaya kepemimpinan terhadap kinerja melalui motivasi sebagai variabel intervening memiliki nilai efek total sebesar 0,161 lebih kecil dari nilai efek total etos kerja terhadap kinerja melalui motivasi sebagai variabel intervening sebesar 0,432. Untuk itu, perlu dilakukan penelitian lebih lanjut baik sifatnya mengulang, memperluas, maupun memperdalam dengan meniliti variabel pelatihan, variabel disiplin kerja, variabel kompetensi, terkait dengan kinerja.

\section{Daftar Pustaka}

Arsad, M. (2017). Pengaruh Etos Kerja Dan Lingkungan Kerja Terhadap Prestasi Kerja Di Kantor Kecamatan Anggana Kabupaten Kutai Kartanegara. E Journal PIN: Pemerintahan Integratif, 5(1), 135-147. http://ejournal.pin.or.id/site/?p=1175

Batubara, S. S. (2020). Pengaruh Gaya Kepemimpinan terhadap Kinerja Karyawan pada Departemen Pengadaan PT INALUM (Persero). Liabilities (Jurnal Pendidikan Akuntansi), 3(1), 40-58. https://doi.org/10.30596/liabilities.v3i1.4581

Ekhsan, M. (2019). Pengaruh Motivasi dan Disiplin Kerja Terhadap Kinerja Karyawan PT.Kahatex. Jurnal Ekonomi Dan Kewirausahaan, 13(1), 1-13. https://doi.org/10.36778/jesya.v3i2.161

Fatchurozi, Sunaryo, H., \& Wahono, B. (2018). Pengaruh Locus of Control,Gaya Kepemimpinan Dan Komitmen Organisasi Pada Kinerja Karyawan Bank Indonesia Malang. E-Jurnal Riset Manajemen, 16-27.

Febrianti, R., \& Triono, J. (2020). Analisis Pengaruh Kepuasan Kerja Dan Motivasi Terhadap Kinerja Karyawan Dengan Komitmen Organisasional Sebagai Variabel Intervening (Studi Pada Karyawan Outsourcing PT Semeru Karya Buana Semarang). Universitas Diponegoro, 1(2), 109-115.

Giantari, I., \& Riana, I. (2017). Pengaruh Budaya Organisasi terhadap Motivasi Kerja dan 
Kinerja Karyawan Klumpu Bali Resort Sanur. E-Jurnal Manajemen Universitas Udayana, 6(12), 245565.

Hendriyaldi, H. (2019). Pengaruh Gaya Kepemimpinan Dan Budaya Organisasi Terhadap Kinerja Pegawai Pada Kantor Camat Pangkalan Jambu Kabupaten Merangin. Jurnal Benefita, 1(1), 26. https://doi.org/10.22216/jbe.v1i1.3442

Rukmana, I. J. (2020). THE INFLUENCE OF LEADERSHIP AND MOTIVATION ON EMPLOYEE PERFORMANCE. Jurnal Manajemen Dan Bisnis, 4(01), 1689-1699.

Salahudin, S. N. bin, Alwi, M. N. R. bin, Baharuddin, S. S. binti, \& Halimat, S. S. binti. (2016). The Relationship between Work Ethics and Job Performance. 465-471. https://doi.org/10.15405/epsbs.2016.11.02.43

Veliu, L., Manxhari, M., Demiri, V., \& Jahaj, L. (2017). the Influence of Leadership Styles on Employee'S Performance. Journal of Management Social Sciences Vadyba Journal of Management, 31(231), 59-69.

Wiyono, G. (2020). Merancang Penelitian Bisnis Dengan Alat Analisis SPSS25 \& SmartPLS 3.2.8 (Kedua). UPP STIM YKPN. https://doi.org/10.1155/2010/706872

Wowor, W. Q., Sumayku, S. M., \& Sambul, S. A. P. (2019). Pengaruh Gaya Kepemimpinan Terhadap Motivasi Kerja Karyawan Pada PT. Matahari Departement Store di MegaMall, Manado. Jurnal Administrasi Bisnis, 8(2), 107. https://doi.org/10.35797/jab.8.2.2019.23626.107-112 